\title{
Participation in advanced age: enacting values, an adaptive process
}

Paul Sugarhood*, Pamela Eakin†, Lynn Summerfield-Mann‡

* London South Bank University

Department of Allied Health Sciences, School of Health and Social Care, 103

Borough Road, London, SE1 OAA

p.sugarhood@Isbu.ac.uk

$\dagger \quad$ London South Bank University

Department of Allied Health Sciences, School of Health and Social Care, 103

Borough Road, London, SE1 OAA

eakinpa@lsbu.ac.uk

$\ddagger \quad$ London South Bank University

Department of Allied Health Sciences, School of Health and Social Care, 103

Borough Road, London, SE1 OAA

summerl@|sbu.ac.uk 


\section{ABSTRACT}

The concept of participation, introduced through models such as the International Classification of Functioning, Disability and Health, has become increasingly important in health and social care. However, it has not been consistently defined or operationalised, and there is very limited research into participation in the context of advanced age and disability. This article reports a study which explored participation from the perspectives of communityliving people aged over 80 years with physical rehabilitation needs. Using a grounded theory methodology, 11 participants aged 81 to 96 years were recruited from a National Health Service Trust in the United Kingdom. The main finding was that participation was experienced as the enacting of values. Values provided the motivation for specific ways of participating in life, guided actions and behaviours, and were the means through which participation was interpreted. Commonly enacted values were: connecting with others; maintaining autonomy; affirming abilities; doing the best you can; being useful; maintaining self-identity, and pursuing interests. A process was evident whereby participation was challenged by deteriorating health and losses and the participants adapted (or not) to overcome these challenges. To promote participation in advanced age, health and social care policy and practice must consider the values important to older people. Interventions should be congruent with these values and promote strategies through which they can be enacted.

KEYWORDS - participation, ICF, advanced age, disability, values 


\section{Introduction}

The concept of participation is a subject of increasing interest and importance in health and social care. It has been argued that participation should be the ultimate goal of rehabilitation for people with disabilities (Cardol, de Jong and Ward 2002, Desrosiers 2005), based on the idea that human functioning and health are not purely a consequence of the presence or absence of disease and impairment. Rather, they are the outcomes of a dynamic interaction between the individual, their health conditions, activities performed and societal involvement.

Participation has been defined in various ways but usually in terms of performance of activities, social roles and involvement in society. The International Classification of Functioning, Disability and Health (ICF) (World Health Organization [WHO] 2001) explicitly incorporates participation in its conceptualisation of health and disability. The ICF aims to provide a common language and framework for a wide range of uses at individual, institutional and societal levels e.g. in clinical settings, epidemiology, social policy, education and research (WHO 2001). It is a classification system which proposes that the components of functioning and disability are [a] body structures and functions, [b] activity and [c] participation, representing functioning successively "at the level of body or body part, the whole person, and the whole person in a social context" (WHO 2001: 10).

Participation is defined in the ICF as "involvement in a life situation" and refers to what a person actually does in their current environment (WHO 2001). There are nine classification domains: learning and applying knowledge; general tasks and demands; communication; mobility; self care; domestic life; interpersonal interactions and relationships; major life areas, and community, social and civic life.

There has been criticism of the ICF's stance on participation. There is very limited conceptualisation of participation beyond the definition "involvement in a life situation" (Whiteneck and Dijkers 2009), and personal meanings or any subjective nature of 
functioning and disability are not accounted for (Ueda and Okawa 2003, Hemmingsson and Jonsson 2005). The two qualifiers used to indicate level of functioning or disability "capacity" (to execute a task or activity) and "performance" (what an individual does in their environment) - both relate to behaviour observable from the outside and do not inevitably indicate that a person is experiencing participation.

Participation, as introduced by the ICF, is clearly an important concept for people for whom ill health or disability might result in reduced opportunities for participation. One such group is people in the so-called 'fourth age' (Lloyd et al. 2012). Lloyd et al. (2012) define the fourth age as a combination of [a] chronological age, [b] loss of function, autonomy, agency or selfreliance and [c] approaching death. This stands in contrast to a 'third age', defined in terms of a younger age group (but still over 65 years) who are successfully ageing and remain fully active agents in their own lives. There is a growing recognition of the need to understand the nature and needs of 'older' older people in their 80s upwards and that, so far, they have been significantly under-represented in health and social care research (Age UK 2013).

While many individuals live healthy and active lives in advanced age, at a population level there is a direct correlation between increased age and disabling conditions that require health and social care services (Department of Health 2001). Ageing and disability are each associated with participation restriction (Law 2002), so those experiencing both are at double risk. One response to the challenges posed by demographic changes is the idea of 'ageing in place', which comprises the goals of avoiding or deferring institutional care and remaining an active participant in society in later life (Vasunilashorn et al. 2012). Older people increasingly live in their own homes in the community even if they experience ill health, functional loss or disability, and United Kingdom (UK) health and social care policy and guidance aim to promote this through services such as intermediate care (Department of Health 2001) and homecare re-ablement (Care Services Efficiency Delivery 2009). These documents and the services developed from them tend to focus on preventing hospital 
admission, maximising independence in essential activities of daily living and minimising the need for social care rather than enabling active participation in society. In a review of interventions that might support older people to live their chosen lifestyles, Allen and Glasby (2010: 2) state there is:

"a bias...towards interventions that promote physical health, with less attention paid to what may well prove to be the crucial issues of social contact, involvement and engagement, and the opportunity to make a valued contribution to society."

If participation is indeed essential to health and wellbeing, its neglect in intermediate care and re-ablement services poses a threat to older people 'ageing in place'. Greater understanding of the concept of participation in advanced age could assist development of these interventions.

Whilst considerable research into the concept of participation has been conducted since publication of the ICF in 2001, there have been very few studies of people in advanced age. Three studies have explored personal experiences of participation. Haak et al. (2007), interviewing eight people from the general population aged 80-89 years who lived alone in an urban area of Sweden, identified a core category of "home as the locus and origin for participation" (Haak et al. 2007: 98). They found that participation gradually changed from taking part in physically demanding activities out of the home to socially oriented activities within the home. This shift, caused by declining health, was characterised as moving from "actor" to "spectator". Two main categories were identified: "performance-oriented participation" (i.e. engagement in the performance of activities) and "togetherness-oriented participation" (i.e. a sense of togetherness with other people).

Vik et al. (2008) explored how three adults in Norway aged 72, 82 and 86 experienced participation while receiving home-based rehabilitation following a hospital admission. Being in charge and having control emerged as essential features of participation. The authors 
placed the concept of "agency" as central to the experience (Vik et al. 2008). Witsø, Vik and Ytterhus (2012) interviewed ten people aged 72 to 89 years living in an urban area of Norway who required home care services. A core category of "keeping up dignity and pride" was identified (Witsø, Vik and Ytterhus 2012). The main project in the lives of the participants was to maintain a sense of dignity and pride, fending for themselves at home as much and for as long as possible, in the face of changing functional capacity.

These studies advance understanding of the concept of participation in advanced age beyond the brief ICF definition. The different (but not contradictory) findings emphasise [a] the personal nature of participation, in which individual meanings play a fundamental part in whether and how participation is experienced; [b] autonomy and agency might be important features of participation; [c] the environment, and particularly the social environment, plays a vital role in providing opportunities for participation; and [d] challenges to participation are posed by advanced age and (for some) disability, and these challenges require an adaptive response if the older person is to maintain a satisfactory sense of participation.

Cross-sectional research to examine levels of participation or participation restriction among older people has been conducted in Canada (Desrosiers et al. 2009), the UK (Wilkie et al. 2006) and Australia (Fairhall et al. 2011). These studies suggest a direct relationship between increased age and decreased participation, with participation restriction most evident in those aged over 80 years (Wilkie et al. 2006, Desrosiers et al. 2009). However, the results are heavily reliant on the measurement tools used to capture participation. Many instruments have been developed to measure participation, for example the Assessment of Life Habits (Fougeyrollas et al. 1998), Impact on Participation and Autonomy (Netherlands Institute for Health Services Research 2007), Participation Profile (Ostir et al. 2006) and Participation Scale (van Brakel et al. 2006). No tool, however, has been specifically developed for (or validated on) people aged over 80 years. It is clear that participation is not easily measured and remains a challenging concept to operationalise. No gold standard 
instrument has yet emerged, and it could be questioned whether developing such a gold standard is realistic given the complexity of the concept. The main problems in instrument development relate to which domains comprise participation and the need to include personal meanings and the subjective nature of functioning and disability.

In summary, despite its growing significance in health and social care, there is a lack of consensus on the definition, conceptualisation and operationalisation of participation. The principal research question of this study therefore was: What does participation mean from the perspectives of community-living people aged over 80 years who experience functional loss or disability? The aim was to gain a rich understanding of the concept, in particular from those who had not been represented in previous research, those from diverse ethnic and cultural backgrounds, in a variety of home living arrangements and in the older age range of those over 80 (e.g. aged over 90 years).

\section{Methodology}

A grounded theory methodology was used, based on the methods of Glaser and Strauss (1967) and Glaser (1978, 1992) combined with the social constructionist theoretical perspective of Charmaz (2006). This perspective focuses on grounded theory as a way to study processes and create interpretive abstract understandings (rather than explanations) of the world. It prefers "theorising" to "theory" and "assumes that neither data nor theories are discovered. Rather, we...construct our grounded theories through our past and present involvements and interactions with people, perspectives, and research practices" (Charmaz 2006: 10).

\section{Setting and participants}

The setting was a National Health Service (NHS) Trust in outer London in the UK. The population served by the Trust is characterised by ethnic diversity and high levels, compared with UK averages, of socio-economic deprivation. Participants were recruited from 
intermediate care and community health services, comprising a day hospital, inpatient rehabilitation unit and four locality-based community health teams.

Inclusion criteria were: being aged 80 years or over; functional decline (defined as loss of independence with personal or domestic activities of daily living or both); living in one's own home (including sheltered accommodation but excluding residential and nursing homes); no or mild communication problems (that is, able to participate in an interview in the English language); and the mental capacity to make an informed decision about taking part in the study, as defined by the Mental Capacity Act 2005 (Great Britain, Parliament 2005).

Eleven participants were recruited, comprising six women and five men aged 81 to 96 years from a range of ethnic, cultural and social backgrounds and with varying levels of functional loss. Details are given in Table 1. Pseudonyms are used throughout the article.

$<$ Insert Table 1 about here $>$

\section{Data collection and analysis}

Data collection and analysis proceeded simultaneously. The main data collection method was in-depth semi-structured interviews. One interview was conducted with each participant by the first author, although there were up to three contacts between researcher and participant (to provide information, gain informed consent and undertake the interview). Interviews lasted between 35 minutes and 1 hour 37 minutes, were audio recorded and transcribed in a readable "written style" rather than an "oral style" of fully detailed intonation, pauses and overlaps (Kvale and Brinkmann 2009).

The starting point in interviews was participation in the sense introduced by the ICF (WHO 2001). Questions focused on what participation meant to the person; what activities, life situations or roles were important in providing a sense of participation; what specific aspects 
of these were key to experiencing participation; and how the combination of advanced age and functional loss or disability influenced participation. The word participation, in the sense this study wanted to explore, is not necessarily one that is in everyday use. Other words and phrases were also used to convey the concept, most commonly 'involvement' and 'involvement in life' or 'life situations'. The aim was to prevent the interviews becoming semantic discussions of the word participation and to lead them in a narrative direction in which participants could talk about their experiences (Van de Velde et al. 2010).

All participants chose to be interviewed in their own home. Many participants talked at length before and especially after the interview, and several took the researcher on a 'tour' of the home or showed photographs or photograph albums. Extensive field notes were recorded immediately after each home visit and formed part of the dataset.

Data analysis comprised a three-phase (but iterative) coding process of constant comparison (Glaser 1978, Charmaz 2006). First was initial coding, in which data were analysed line-by-line with an open attitude as to interpretations and meanings. Second came focused coding, in which decisions were made about which initial codes made the greatest analytic sense in terms of categorising the data. These focused codes were raised into broader categories, which helped to integrate and organise the initial codes and guided further data collection. Third was theoretical coding, which explored relationships between the focused categories and integrated them into a theoretical framework (Glaser 1978).

Memos were written extensively, documenting all aspects of the research process and decisions taken during data analysis. Data were collected and analysed until "theoretical sufficiency" (Dey 1999) was achieved i.e. there was a meaningful analysis which fitted the data, was credible and coped adequately with new data without requiring continual modification. 


\section{Recruitment strategies}

Participants were identified and approached initially by staff working in the services where the study was based. Staff members alerted the first author to all potential participants who met the inclusion criteria and they agreed in advance which individuals would be approached. If someone was willing to consider taking part, contact was then made by the first author to provide information and discuss consent. The guiding principle was to recruit "information-rich cases" (Patton 2002: 230). The initial recruitment strategy was maximum variation within the inclusion criteria, enabling categories to be constructed that cut across the heterogeneous group of participants. Later, theoretical sampling was used. Participants were selected based on whether they would offer interesting comparisons and help fill out the properties of categories or the emerging theory. Examples included selection of participants who lived in multi-generation households or who had a diagnosis of depression.

\section{Trustworthiness}

The framework outlined by Lincoln and Guba (1985) was used to promote trustworthiness of both the research process and the end product. Credibility and dependability were enhanced through prolonged fieldwork (21 months) and immersion in the data; a detailed audit trail of coded transcripts and memos; triangulation of two data collection methods (interviews and field notes); checking the emerging analysis by asking new participants questions about whether and how it fitted with their experiences; and formal and informal peer examination by the authors, academic colleagues and healthcare professionals from the host NHS Trust to promote reflection. Transferability of the findings should be judged based on the descriptions in this article of the research context, setting and participants. The main strategy to promote confirmability was reflexivity. Reflective logs were written throughout, from initial planning through to data collection and analysis. They attempted to turn what could be perceived as a problem (the bias of subjectivity) into an opportunity to promote rich insight, question assumptions and enable public scrutiny of the research study (Finlay 2002). 


\section{Ethics}

Issues arose concerning power relationships, psychological intrusion from interviewing and misunderstanding of professional or social boundaries. The social constructionist approach of joint-meaning making supported power being divided between the researcher and participants, albeit imperfectly and to different degrees. Adjustments were made during interviews to address pain, fatigue, speech or visual impairment. If distress was apparent, the researcher sat with the participant, provided re-assurance, acknowledged and validated experiences, and reminded the participant they could continue or stop the interview or topic without needing to explain why. Care was taken to shape interviews with a thorough "phase of emergence" (Corbin and Morse 2010).

Regarding boundaries, several participants requested advice about daily living equipment or home adaptations. A decision was taken as to whether this was relevant to the research topic or prompted by participants' awareness the interviewer was an occupational therapist. If the latter, the request was acknowledged but dealt with at the end of the interview.

\section{Findings}

A core category was identified: participation as enacting values. For the people in this study, participation was experienced through a set of values. Values were moral or ethical beliefs about what was perceived to be important, worthwhile, right or wrong (in terms of what was morally correct, justified or acceptable) and good or bad (in terms of what was desirable or approved of, of a high standard, enjoyable or satisfying). It was through the enacting of values held by each person that he or she felt they were participating and being involved in life. Some participants, when asked what participation meant to them, talked directly about values they held, with some actually naming them as 'values'. For others, values were implicit in what they said. 
The values a person held motivated them to participate in particular ways, guided their actions and were the means through which participation was interpreted. For Kannan, for example, mixing with other people and helping them was important and the right thing to do. He therefore performed a service for friends and acquaintances who had difficulties with official correspondence (because they lacked familiarity with the system in the UK or did not speak English). He also strongly believed in not discriminating against people based on their "class or creed". Despite his health problems and reduced functional abilities, Kannan was able to enact his value of non-discrimination when helping others. He gained a strong sense of participation because he could still act in a non-discriminatory way consistent with his professed values. How he interpreted his involvement in life, based on his values, was fundamental to his experience of participation.

Participation in advanced age and in the face of poor health and declining function was not, however, simply a continued enacting of values in the same way as had happened earlier in life. The participants frequently described challenges to participation (i.e. to enacting their values) and how they adapted (or did not adapt) to these challenges. A theoretical framework was constructed in which participation as enacting values was viewed as part of an adaptive process. This process is illustrated in Figure 1.

$<$ Insert Figure 1 about here $>$

The main arrow across Figure 1 represents participation during the course of advanced age, comprising the core category of participation as enacting values. Time passes from left to right. Each loop or spiral represents challenges to participation and the person adapting to maintain participation. This open process was circular, back and forth and on-going, involving actions and interactions between the inter-related and mutually-influencing elements. Ronan, for example, required significant assistance from carers to remain living in his flat. He was happy to accept this adaptation because it fitted with his values - he was 
less concerned with physical independence than with connecting with friends by telephone and pursuing his highly valued interest of reading literature and philosophy.

The research participants were interviewed at one point in time, so for each individual data were constructed at one moment within this process of constant change. It might be that each loop was a separate event or issue. Grace, for example, had been challenged successively over about 20 years by the effects of rheumatoid arthritis, loss of role and autonomy on retirement, and then reduced mobility (and ability to attend a highly-valued day centre) caused by cellulitis. She gradually implemented various adaptations to meet each of these challenges, such as adjusting her expectations of what she could and could not do, engaging in mentally stimulating rather than physically demanding forms of participation, and moving out of the family home (where she lived with her son, daughter-in-law and grandchildren) to her own flat, where she could feel more autonomous and less dependent on routines imposed by others. It was more often the case, however, that participants faced several simultaneous challenges to participation, or that a challenge was not resolved or adapted to as a one-off event but revisited and re-enacted over a period of time.

Challenges to a person's ability to enact their values led to a struggle which (at the time of the interview) some felt they were winning and some losing. How individuals interpreted and ascribed meanings to the process determined their perceived level of and satisfaction with participation. The rest of the Findings section details the specific values, challenges and adaptations illustrated in Figure 1.

\section{Participation as enacting values}

The specific values enacted to provide a sense of participation varied across the participants. However, a number of the categories developed during focused and theoretical coding reflected seven commonly held and enacted values. 
Connecting with others. Almost universally, connecting with others was what mattered most and was most highly valued. When feeling linked to other people - whether face-to-face in a social situation, jointly performing an activity with others, talking on the telephone, belonging to a family or other social group, or simply by feeling a connection to the outside world - the participants experienced a sense of participation. Words used to express the experience included "connecting", “mixing", "communicating", "talking", “associating", “making contact", "sharing", "passing time" or "just being with" other people, a "social life" and "being a member" (of a family, group or community).

For Grace, being a member of a day centre and developing friendships with others was explicitly stated as an essential aspect of participation:

"I joined this club. And it's the best thing l've ever done. I go there Monday, Tuesday, Wednesday and Friday... We have a good old natter, you know, and gossiping and all that. Then we, we all go to our separate ways. But we ring each other, you know, we ring each other, if you want something. Like when l'm doing a crossword and I'm stuck I'll ring one of them. ... To communicate with other people. That's me." Grace

Connecting with others was also enacted in ways which did not involve actually being with people. The value could be achieved through a sense of belonging to a family or social group. Jasbir Singh, for example, attended and undertook voluntary work at his local gurdwara (Sikh temple). He described a strong sense of participation and being involved in life through feeling connected to this wider social, cultural and religious group, but said the sense of connection and belonging was just as strong when sitting on the sofa alone at home as when actually attending the gurdwara. Other participants described feeling connected to the outside world through watching a television documentary or travel programme, keeping up-to-date with current affairs or events in the local neighbourhood, listening to the radio, reading a newspaper or book, or sitting at home in an armchair looking out of the window watching people walk past. 
There was a range in the depth of the experience of connecting with others, depending on who was being connected with and how. Connecting with others, as an enacted value that provided an experience of participation, emphasised emotional attachment and the feeling of belonging rather than merely being in the presence of others. Harry described an intense sense of connection with his wife. They had been married and lived together for 55 years:

"We have this unison thing for some time. We look at each other and we both want to say 'Would you like a cup of coffee?' and the other one can say I was just about to say that to you. We have that. Lot of people don't have that, but we do. We can look at each other and the unison thing comes out. Lovely." Harry

Maintaining autonomy. Maintaining autonomy played an important role in participation, and there were two aspects. First, the ability to act as one wished, to do the things one wanted to do. Second, the ability to make decisions for oneself without feeling overly constrained by external influences. Both types of autonomy were often referred to as being "independent". A sense of participation was gained when participants were able to act as they wished or to make decisions for themselves. Conversely, participation was hindered when they were not able to act or make decisions in a satisfactory way.

Autonomy was in some ways a counterpart to the value of connecting with others. Autonomy emphasised participation as an individual, the personal perspective of independent action and decision-making. Irene, when describing the impact of needing twice daily home visits from formal carers, stressed the importance of autonomy:

"She [carer] gets everything ready. Washes me. Comes up and she says anything else? And I say no I'm all right. And she says no, she, I say no I'm ok, I said I can do it myself. So then, very independent, they say to me you're very independent. I say I know I am, I like to do what I can, I like to do for myself... I, well I like to do everything myself but I just can't do it at times, so, but there you are. I get, do what I can, yeah... Well I'm satisfied with what I get. What they do helps me a lot, and otherwise I can do my own." Irene 
Affirming abilities. Despite much discussion of physical and functional loss, and what could no longer be done or participated in, participants frequently affirmed their abilities and what they could and did still participate in. Value was placed on affirming abilities that the person still had and ways of participating in the here and now. What was valued was a sense of mastery and pride that the participant was still a capable and effective actor - at least in some ways and on some occasions - and not only a spectator or person requiring care and support.

This value was illustrated in the following extract:

"I mean, you can't do the things like you could do twenty years ago, or fifteen years ago, you know? You can't do all those, so, I mean, I used to pass so much time, what with the children, getting them ready to school, doing ironing, doing cooking, doing all the housework. But I still do quite a lot...And I always keep the place tidy, even when my daughter comes she says 'My god, you keep your place neat and tidy'." Kalinder

Kalinder had described her important past life roles of being a wife, mother and homemaker. Although she no longer held these roles in the same way, she now gained a strong sense of participation through continuing to perform household activities. Although she could not do what she did 15 or 20 years ago, she affirmed and was proud of her remaining abilities and continued participation in life.

Maintaining self-identity. When participants thought and talked about participation, the need for a sense of continuity with the past was frequently evident. An orientation backwards to the past rather than forwards to the future was a common feature of the interviews. Value was placed on maintaining self-identity, on ways of participating in life that preserved a sense of who the person had been and still was. This could be achieved by affirming current abilities and participation, but also by continuing to pursue the same interests as in the past, using skills and experience from the past in the present, continuing to fulfil some life roles (even if in an altered way) and, perhaps most commonly, interpreting the present through 
reflection on the past. A sense of participation could be gained either by performing activities that were congruent with self-identity or, in the face of reduced ability to act, telling stories about or reflecting on past examples of participation.

Differences between the past and present could be regarded positively or negatively. Grace considered her current participation to be greater than during her working life. Membership of her day centre and social club had opened up new horizons for participating in life and provided a deep sense of continuity with her past identity. She described going back to her youth:

"I've had so much fun in life, I, with this retirement, than I used to when I was young. More interests and more life and more enjoyment, in life now, than I used to when I was young. Because when you were young, all you did was concentrate on work. Get up, go to work, get up, go to work. But now, I do, I do so many [activities]... You know, we've come back to our youth. Learning and discovering new things, and meeting new friends." Grace

Ella, however, was very upset at no longer being able to participate in valued activities (e.g. painting and travelling) and loss of roles (e.g. being a committee member). When sharing her current experiences about participation in life with the researcher, Ella revealed how important the value of maintaining identity was for her. When she looked back at more than 30 years of very active retirement, she became tearful. She debated with herself and seemed unsure what she could and could not now do:

"Sewing. I find it difficult, I'll sew and knit. I don't know if can knit. I knit, I paint. I can do anything. Cook. Yeah. I cook my meals. I can bake. There's nothing I can't do, I couldn't do, I could. But now, I can't." Ella

While Grace was able to establish a link between past and present participation and feel she was maintaining her self-identity, Ella saw a clear break between her past and present, between who she had been and who she was now. She also worried that further loss of health and function might result in additional loss of self-identity. 
Doing the best you can. Participants placed great value on doing the best they could to participate and be involved in life. Different words and phrases were used to describe this idea: "I just do the best I can" (Kannan); "I have to try" (Lena); "it's not always easy, but I try very hard" (Ella); "you mustn't let yourself go" (Harry); "you've just got to make the best of it" (Kalinder), and "you've just got to get on with it" (Irene).

Doing the best you can involved putting in physical or mental effort to overcome obstacles or adversity and so perform valued activities. It was sometimes portrayed as hard work, with imagery of an on-going struggle against gradually increasing age, illness and disability. The struggle could be frustrating, uncertain, upsetting and a cause of worry, distress or disappointment, but also rewarding and successful. Harry greatly enjoyed books, and had talking books delivered from the local library service. He did not let non-delivery of the books on one occasion prevent him from engaging in this valued activity, despite the difficulties entailed in going outdoors due to his visual and mobility impairments:

"It's a question of getting out. You mustn't give up life. You have to get out as best you can... We have the library girls come round. And I get seven books. They come regularly, large as life. But, the other day or whatever it was, the girl was ill and one went away. I had to go up the library myself...l've a bit of a journey going there." Harry

Being useful. A value frequently discussed in relation to participation was that of being useful. Participants wanted to be useful, to have a sense of importance. In some ways this idea ran counter to the typical situation many participants found themselves in of being in need, of requiring support and help from other people. Not feeling useful (at least in some situations) could lead to a sense of non-participation and uselessness.

Enacting the value of being useful was achieved by doing things for or helping others, giving something in return for help received (reciprocity), taking responsibility for something, or 
being a figure of respect. George, who was no longer able physically to do things for others, could help in other ways:

"Financially. That's the only way. If I have a few bob, when they come and said, you know, they're short of anything and I have it, I give them." George

For Jasbir Singh, setting a good example, being a role model for children and younger generations, and being a figure of respect within the family and community provided a sense of usefulness and hence participation:

"There's that position, all right? You don't get any money but that position is good enough for me. And the main thing, they, they respect me. They respected, they thought he is a good man like and this and that. That's, that's what made you happy." Jasbir Singh

Pursuing interests. Pursuing interests was highly valued by many participants. Interests were activities or ways of spending time that the person found stimulating, enjoyable, satisfying or fulfilling. During the interviews, several participants focused initially on specific interests such as hobbies or leisure activities when asked about participation. Harry, for example, gave a detailed account of his past interests in photography, working on an allotment and bowling. Current experiences of participation were often interpreted through the extent to which the person was able to continue pursuing key interests and activities.

A very wide range of interests were mentioned in the interviews. Most were developed in or linked to the past, although new interests were also described. The interests related to hobbies or leisure activities, work and career, family or community roles and cultural or religious affiliations. The specific interests that a person pursued were often closely related to values that they held. George, for example, loved playing dominoes. He also had a strong belief in the value of connecting with other people and having a chat. So, when he felt well enough, he walked along the corridor of his sheltered housing scheme to the common living room to see if any other residents were there with whom he could play dominoes. Thus it 
was not only the pursuit of specific interests in and of themselves that mattered, but also that other values could be enacted through pursuing these interests.

\section{Challenges to participation}

As depicted in Figure 1, various challenges to participation arose in advanced age. Some of the factors (e.g. loss of a spouse) were difficult to cope with in their own right. What is of relevance here is how (and to what extent) these challenges had an impact on the ability to enact values and hence participation.

Most often, challenges were multiple and cumulative. Lena, for example, found it very difficult to walk following her stroke, which meant she was unable to get out of the house and take part in valued activities such as visiting friends and shopping. She then became depressed and lost confidence in her abilities to perform activities within the home, such as cooking, which further restricted her sense of participation. The more factors, and the more they reinforced each other, the greater the risk to participation. What was consistent across all the participants was a sense that their participation was increasingly challenged as their health deteriorated, they experienced various losses and there was an increasing mismatch between their capabilities and the environments in which they lived.

Being let down by health. Participants reported that their health challenged participation, and this was often characterised as being let down by health. Participants felt let down in that they experienced changes to their bodies and their underlying capabilities; their bodies were no longer able to function in the same way as in the past. Such changes could occur suddenly (e.g. due to a heart attack) or gradually (e.g. due to rheumatoid arthritis). Health was sometimes depicted in terms of these 'objective' medical conditions (heart failure and rheumatoid arthritis). It was much more common, however, to describe health in terms of the 'subjective' lived body - fatigue, pain, breathlessness, stiff or weak joints and muscles, unsteadiness, reduced vision, forgetfulness, loss of concentration and confidence, and low 
mood.

Harry, for example, greatly valued mixing with other people but now found it very difficult to get out to visit people or attend social occasions. Fatigue and tiredness limited his participation:

"See we went out last night, an invitation to a dinner. But truthfully at ninety years of age having a dinner like that is too much for us, it's a long day. It's just the fact that you're exhausted, you're knackered as it were." Harry

Losses. Loss was very common. As well as poor health and functional decline, there was loss of people and social relationships (e.g. the death of a spouse or friends, neighbours moving away or the closure of a social club); life roles (e.g. worker, spouse, parent, carer, volunteer); and performance of activities (e.g. walking outdoors, gardening, shopping, travelling abroad). These losses put participation at risk in that there might be reduced or altered opportunities for enacting values.

Environmental influences. The participants in this study gave examples where the environment exerted a negative influence either on their opportunities to participate or their overall sense of participation. All aspects of the environment - physical, social, institutional and cultural - were mentioned.

Examples of challenges to participation posed by the physical and institutional environments were lack of places to sit and rest when trying to walk to the local shops (Kannan) and withdrawal of Wi-Fi provision from a housing estate that meant Ella could no longer access the internet or communicate with relatives abroad via email.

What were mentioned most frequently, however, were social and cultural aspects of the home and neighbourhood. Some perceived a loss of social cohesion. This often occurred for 
people who had lived in the same property for many years and seen longstanding neighbours and friends move away or die. The attitudes and expectations of other people could also present a challenge to participation. This happened when such attitudes were based on what were perceived as (unhelpful and inaccurate) stereotypes about what an older person could or should do. Ella told a story of when she was admitted to hospital and her self-identity and sense of her own abilities were undermined by the attitudes of a healthcare professional:

"When I had that fall, when I went to the [name of hospital], the doctor was talking to my son and his girlfriend. As if I weren't there. But I didn't worry. I keep quiet. But I tell him [son] 'She was talking to you, not talking to me.'I am capable, I am quite capable of answering. Because when you get old they think you are stupid." Ella

\section{Adapting to maintain participation}

Challenges to participation triggered a process of adaptation, of finding ways to continue enacting values. The participants in this study appeared to have an inner drive to participate in life. They all either adapted in some way to maintain participation or became upset or distressed if they were not able to adapt.

Some participants (e.g. Grace and George) could be interpreted as successfully adapting to almost all the challenges faced, with Grace even saying she experienced a greater sense of participation now than when she was younger and in better health. Most participants adapted to some challenges but not others and portrayed their participation as satisfactory and fulfilling in some ways but wished that things could be better in others. Two (Ella and Lena) were clearly dissatisfied with their participation and had not successfully adapted, at the time of the research interview, to the challenges they faced.

Adapting to maintain participation comprised many strategies but took two main forms. While these are presented separately, what was evident was a dual simultaneous process of 
thinking about and interpreting challenges to participation, and acting on the challenges. This was not simple or linear, but involved on-going negotiation both with oneself and with others in a back and forth, circular process.

Interpretive processes, thinking about things in a different way.

"And you see, what happens to you in life is not as important as what you think it is. It's what you think it is that affects you. Which is, you see, that's what I said. Your thoughts, your life is what your thoughts make it." Ronan

What Ronan expressed here was that there were challenges in life, including challenges to participation. "What happens" to you could include being let down by health, losses and so on. These events, however, did not define the experience on their own. What an individual person thought about the event - how they interpreted it - was what mattered most. One way that the participants in this study adapted to the challenges they faced was to think about, interpret and make sense of their situation. Challenges to participation were mediated through individual personal interpretations.

The main interpretive process participants went through to adapt to participation challenges was a process of accepting their current situation. The words "accept", "accepted" and "acceptance" came up frequently in the interviews, although the idea was also conveyed through phrases such as "you can't expect to do the same things", "I've become used to it", "take things as they come", "you've just got to get on with it" and "you make the most of it".

What participants described was changing their expectations (i.e. what they believed their participation should be like) to match the reality of their current situation (i.e. what it was actually like, as they perceived it). The closer the match between expectations and reality, the greater the satisfaction with experiences of participation. When George discussed what could be considered the greatest loss - his own approaching death - he said he was 
reconciled with this and happy that he had lived a full life. He said he was still participating in life and experiencing wellbeing through how he interpreted his situation:

"But that's [going outdoors to visit friends] finished now and l've finished, where life is, where age is concerned, that's plays a great part of it because, I'm well in my nineties, so. You don't live forever. So, you expect it and just got to get along. By being satisfied. I been satisfied with the life as it goes. Just satisfied. No moaning, no regrets, no nothing. Just satisfied... I feel I reach the stage now where I am just satisfied with whatever happens to me, you know. I can't move about as I should. I am still grateful for life." George

Selecting forms of participation and how they are enacted. Two main ways of taking actions to adapt to and overcome challenges to participation were identified. First, participants selected forms of participation, choosing what was most important or feasible to continue participating in and what to drop. Second, they adapted how these forms of participation were enacted.

In terms of selecting forms of participation, the choices participants made were often practical, based on what it was feasible to achieve, but always grounded in their values. There was a tendency to move from pursuing more physically demanding forms of participation out of the home to those which were mentally stimulating, contemplative, sedentary and based in the home. Many mentally simulating activities were described in the interviews, including keeping up-to-date with current affairs; reading; learning new skills such as computing or a foreign language; games (e.g. crosswords and television quizzes); creative writing; talking with others; listening to music and radio programmes; and just sitting and thinking on things or reflecting on the past.

In terms of how the selected forms of participation were enacted, this could involve doing things in a different way, adapting the environment or accepting human assistance. One of Norma's greatest interests, for example, was nature and the natural world. Pursuing this interest was a highly valued form of participation, and throughout her life she had enjoyed 
gardening, observing and studying nature outdoors and visiting the Natural History Museum in London. At the time of the interview, she could no longer participate in this way due to limited mobility and not being able to go outdoors. Instead, she sat inside her home and looked at the garden (having placed an armchair next to the window overlooking the front garden), watched the seasons pass, discussed care of the garden with the friend who now looked after it and listened to wildlife programmes on television. She also remembered past enactments of her interest in nature and derived enjoyment and satisfaction from these reflections.

\section{Discussion}

Participation was not experienced by the participants in this study as an objective list of daily activities or social roles, or as frequencies that such activities or roles were performed, as might have been expected from the conceptualisation of participation in the ICF (WHO 2001). Rather, participation was experienced through a set of values. It was through enacting values that the people in this study felt they were participating and being involved in life. Confronted by functional loss and disability in advanced age, there was a process in which enacting values was challenged and each participant adapted (or not) to meet these challenges.

Consideration of personal values - what matters to people - is therefore essential if participation in advanced age is to be promoted. A similar finding was reported by Wright-St Clair (2012) when exploring the experience of being aged in everyday life. The notion of "doing what matters" was of primary importance in advanced age, with engagement in an enduring, compelling pursuit evoking a deep sense of identity and contentment. The ICF (WHO 2001) does not address this issue.

The findings of this study resonate with recent work in social theory by Andrew Sayer, who has argued "people's relation to the world is one of concern" (Sayer 2011: 1) because "we 
are sentient beings who can flourish or suffer" (Sayer 2011: 3). According to Sayer, the act of valuing, or making evaluations of everyday experiences, is foundational to being human and what matters to people should be central to analysis of social behaviour. Values should be thought of as "sedimented valuations that have become attitudes or dispositions, which we come to regard as justified. ... They are more abstract than the particular concrete evaluations from which they derive and which they in turn influence. The relation between values and particular valuations is thus recursive" (Sayer 2011: 25). It is possible for health and social care professionals to gain access to an individual's personal values - what matters to them. Values are not arbitrary but stem from reasoned responses to the challenges of everyday living. In-depth discussion of events, people and objects can therefore enable identification of the values that underlie participation for each person. Values tend to be most easily recognised and articulated when challenged in some way, and involvement with health and social care services most often occurs during such periods of change and challenge. As suggested by Cardol et al (2002: 973), "the patient-professional encounter should be a dialogue through which an individual's values and preferences are discovered."

The findings extend previous research into experiences of participation (Haak et al. 2007, Vik et al. 2008, Witsø, Vik and Ytterhus 2012) through exploring the perspectives of those from different nationalities, ethnicities, in more advanced age and those living with others. While many of the values were evident in the previous studies (e.g. connecting with others, maintaining autonomy), the findings of this study imply that the whole concept of values should be placed at the core of understanding of participation. That is, participation comprises enacting a number of values. It is enacting values - whatever those values might be for different people - that provides a sense of participation.

Research exploring the perspectives of other groups of people has also found values to be an important component of participation. This includes studies of people with chronic pain 
(Borell et al. 2006), acquired brain injury (Häggström and Lund 2008), those "self-identifying with diverse disabilities" (Hammel et al. 2008) and spinal cord injury (Van de Velde et al. 2010). The specific values identified in these four studies closely correspond to those found here, with particular emphasis on maintaining autonomy, being useful and connecting with others. The similarities in the findings suggest there might be parallels between what participation means to people who experience functional loss or disability, whatever their age. Across all the age and disability groups, values - and specifically the enacting of values in the face of challenges - play a fundamental role in participation. These core values should guide policy and practice around participation.

How people adapt to meet challenges to participation is of particular interest to health and social care professionals who provide interventions aimed at promoting participation. One adaptive strategy of this study - selecting forms of participation and how they are enactedparallels "selective optimisation with compensation" theory (Baltes 1997). This theory proposed that older people employ three adaptive processes to meet the challenges of ageing and disability: selecting fewer and more meaningful goals and activities; optimising existing abilities through practice or new technologies; and compensating for the loss of some abilities by finding other ways to accomplish tasks (Baltes 1997). The other adaptive strategy - interpretative processes of thinking about things in a different way - links closely with "response shift theory" (Rochette, Korner-Bitensky and Levasseur 2006). In response shift theory, an event (e.g. a stroke) creates a new reality for an individual. A transition period then ensues in which expectations have to be redefined. This change, or reset of expectations, is the "response shiff", which occurs in a circular (rather than linear) process.

This study supports application of both these adaptive strategies in health and social care services aimed at promoting participation in advanced age. During an encounter with an older person, observing, discussing and building on the person's existing efforts to maintain participation could guide intervention, while new strategies (that the person might not be 
aware of) could also be suggested. There is a tendency in current practice to focus on improving performance of activities, optimising abilities and compensating for deficits (Allen and Glasby 2010). Less attention is paid to selecting forms of participation and, in particular, to interpretive processes of accepting and coming to terms with challenges to participation. Rather than focusing only on changing the reality of participation, might there also be a role for practitioners in enabling people to re-define their expectations? This can be done by providing adequate and timely information, supporting and coaching older people and their families, and facilitating a reconsideration of the relative importance of different values and an adjustment as to what level and type of participation is viewed as optimal (Rochette et al 2006).

While it may be possible for individual health and social care professionals directly to address challenges to participation, there are clearly environmental challenges. The broader social and political spheres have a role to play in overcoming restrictions to participation in terms of local service delivery and policy at regional and national levels. Attempts to improve participation in advanced age therefore must be directed at micro (individual, family), meso (local community, organisational) and macro (wider social, political and economic) levels.

\section{Limitations of the study}

Use of grounded theory enabled an open and exploratory approach which focused on the perspectives and experiences of the participants and facilitated comparison of eleven individuals. Breaking data down into fragmented initial codes resulted at times during analysis in some loss of the complex situatedness of each participant and their individual narrative. However, comparison of initial and focused codes across the participants added depth to the categories in terms of their dimensions and properties and the different ways they could be played out. 
There were limitations in terms of recruitment. First, excluding non-English speakers was a constraint when, as part of theoretical sampling, it was decided to recruit participants who lived in multi-generation households. Many such people in the study location did not speak English. Second, the inclusion criteria might have influenced the findings because those excluded (e.g. people with significant communication difficulties, or unable to give informed consent) could be at particularly high risk of participation restriction. Third, only people who had received intervention from the NHS were recruited. They might be different in some way from those who experience functional loss or disability but who do not receive such services e.g. in their attitudes towards seeking support and care, or in experiencing a 'better' level of participation precisely because they had received the interventions. Fourth, there are potential cohort effects. The values identified were those that mattered to a group of people born between 1914 and 1930. It might be that other (future) generations hold different values.

\section{Conclusions}

To address participation in advanced age, there must be consideration of personal values. The seven values described here could act as a sensitising guide for health and social care policy and practice aimed at promoting participation. In this study, connecting with others was what mattered most and was most highly valued. Enabling people in advanced age to enact the value of connecting with others might therefore be the most important focus in actions to promote participation. Health and social care services in the UK most often target personal care activities, the physical environment and maintaining autonomy (at least in terms of acting and doing things independently). Greater attention should be paid to connecting with others and the social environment.

While this study focused on the personal perspective, through conducting individual interviews, consideration of wider social perspectives would add greater context to the findings. This should include the role played by the values of significant other people in the 
older person's social network, and the influence of broader social and cultural values in developing and maintaining personal values.

While promoting participation might not be the stated objective of many health and social care services for people 'ageing in place', many do already address the issue. Interventions often take place in the home and involve in-depth discussion of personal values and priorities. Such practices should be validated and encouraged if participation is to be addressed and the goal of people being optimally involved in life in advanced age achieved. 


\section{Statement of ethical approval}

NHS ethical approval was granted by the National Research Ethics Committee London Fulham on 27 April 2011 (reference 11/LO/0371). Local NHS research and development approval was gained from the host NHS Trust on 26 May 2011. University approval was gained from the University Research Ethics Committee, London South Bank University on 21 June 2011 (reference UREC 1126).

\section{Statement of funding}

This study was completed in partial fulfilment of the requirements of London South Bank University for the degree of Professional Doctorate in Occupational Therapy. The host NHS Trust part funded the first author for the fees for this course (50\% funding for years 1 and 2 , $20 \%$ funding for years 3 and 4 ). No specific funding was gained for the study.

\section{Declaration of contribution of authors}

The study was completed by PS, with PE and LSM as academic supervisors. All authors contributed to preparation of the manuscript.

\section{Statement of conflict of interests}

The authors declare they have no conflicting interests.

\section{Acknowledgements}

We would like to thank the research participants, who so openly and enthusiastically gave their time and energy to take part in the study and share their experiences. 


\section{References}

Age UK 2013. Improving Later Life: Understanding the Oldest Old. Age UK, London.

Allen, K. and Glasby, J. 2010. Health Service Management Centre Policy Paper. 'The Billion Dollar Question': Embedding Prevention in Older People's Services - 10 'High Impact' Changes. Available online at http://www.birmingham.ac.uk/Documents/college-social-sciences/socialpolicy/HSMC/publications/PolicyPapers/Policy-paper-8.pdf [Accessed 08 March 2015].

Baltes, P.P. 1997. On the incomplete architecture of human ontogeny: selection, optimization, and compensation as foundation of developmental theory. American Psychologist, 52, 4, 366-80.

Borell, L., Asaba, E., Rosenberg, L., Schult, M-L. and Townsend, E. 2006. Exploring experiences of "participation" among individuals living with chronic pain. Scandinavian Journal of Occupational Therapy, 13, 2, 76-85.

Cardol, M., de Jong, B.A., Ward, C.D. 2002. On autonomy and participation in rehabilitation. Disability and Rehabilitation, 24, 18, 970-74.

Care Services Efficiency Delivery 2009. Benefits of Homecare Re-ablement for People at Different Levels of Need. Care Services Efficiency Delivery/DH, London.

Charmaz, K. 2006. Constructing Grounded Theory: A Practical Guide Through Qualitative Analysis. Sage, London.

Corbin, J. and Morse, J.M. 2010. The unstructured interactive interview: issues of reciprocity and risks when dealing with sensitive topics. Qualitative Inquiry, 9, 3, 335-354.

Department of Health 2001. The National Service Framework for Older People. DH, London. 
Desrosiers, J. 2005. Participation and occupation. Canadian Journal of Occupational Therapy, 72, 4, 195-203.

Desrosiers, J., Robichaud, L., Demers, L. and Gélinas, I. 2009. Comparison and correlates of participation in older adults without disabilities. Archives of Gerontology and Geriatrics, 49, 3, 397-403.

Dey, I. 1999. Grounding Grounded Theory. Academic Press, San Diego.

Fairhall, N., Sherrington, C., Kurrle, S.E., Lord, S.R. and Cameron, I.D. 2011. ICF participation restriction is common in frail, community-dwelling older people: an observational cross-sectional study. Physiotherapy, 97, 1, 26-32.

Finlay, L. 2002. "Outing" the researcher: the provenance, process and practice of reflexivity. Qualitative Health Research, 12, 4, 531-45.

Fougeyrollas, P., Noreau, L., Bergeron, H., Cloutier, R., Dion, S.A. and St-Michel, G. 1998. Social consequences of long term impairments and disabilities: conceptual approach and assessment of handicap. International Journal of Rehabilitation Research, 21, 2, $127-41$.

Glaser, B.G. 1978. Theoretical Sensitivity. The Sociology Press, Mill Valley, California.

Glaser, B.G. 1992. Basics of Grounded Theory Analysis: Emergence Versus Forcing. The Sociology Press, Mill Valley, California.

Glaser, B.G. and Strauss, A.L. 1967. The Discovery of Grounded Theory: Strategies for Qualitative Research. Aldine Transaction, New Brunswick.

Great Britain, Parliament 2005. Mental Capacity Act 2005. HMSO, London.

Haak, M., Dahlin Ivanoff, S., Fänge, A., Sixsmith, J. and Iwarsson, I. 2007. Home as the locus and origin for participation: experiences among very old Swedish people. 
Occupational Therapy Journal of Research: Occupation, Participation and Health, 27, 3, 95-103.

Häggström, A. and Lund, M.L. 2008. The complexity of participation in daily life: a qualitative study of the experiences of persons with acquired brain injury. Journal of Rehabilitation Medicine, 40, 2, 89-95.

Hammel, J., Magasi, S., Heinemann, A., Whiteneck, G., Bogner, J. and Rodriguez, E. 2008. What does participation mean? An insider perspective from people with disabilities. Disability and Rehabilitation, 30, 19, 1445-60.

Hemmingsson, H. and Jonsson, H. 2005. An occupational perspective on the concept of participation in the International Classification of Functioning, Disability and Health some critical remarks. American Journal of Occupational Therapy, 59, 5, 569-76.

Kvale, S. and Brinkmann, S. 2009. Interviews: Learning the Craft of Qualitative Research Interviewing (2nd Edition). Sage, Thousand Oaks, California.

Law, M. 2002. Participation in the occupations of everyday life. American Journal of Occupational Therapy, 56, 6, 640-9.

Lincoln, Y.S. and Guba, E. 1985. Naturalistic Inquiry. Sage, Beverley Hills, California.

Lloyd, L., Calnan, M., Cameron, A., Seymour, J. and Smith, R. 2012. Identity in the fourth age: perseverance, adaptation and maintaining dignity. Ageing and Society. Available online at CJO 2012 doi:10.1017/S0144686X12000761 [Accessed 08 March 2015].

Netherlands Institute for Health Services Research 2007. IPA - The Questionnaire Impact on Participation and Autonomy. Available online at http://www.nivel.nl/en/ipa [Accessed 08 March 2015]. 
Ostir, G.V., Granger, C.V., Black, T., Roberts, P., Burgos, L., Martinkewiz, P. and Ottenbacher, K.J. 2006. Preliminary results for the PAR-PRO: a measure of home and community participation. Archives of Physical Medicine and Rehabilitation, 87, 8, 1043-51.

Patton, M.Q. 2002. Qualitative Research and Evaluation Methods (3rd Edition). Sage, Thousand Oaks, California.

Rochette, A., Korner-Bitensky, N., Levasseur, M. 2006. 'Optimal' participation: a reflective look. Disability and Rehabilitation, 28, 19, 1231-5.

Sayer, A. 2011. Why Things Matter to People: Social Science, Values and Ethical Life. Cambridge University Press, Cambridge.

Ueda, S. and Okawa, Y. 2003. The subjective dimension of functioning and disability: what is it and what is it for? Disability and Rehabilitation, 25, 11-12, 596-601.

van Brakel, W.H., Anderson, A.M., Mutatkar, R.K., Bakirtzief, Z., Nicholls, P.G., Raju, M.S. and Das-Pattanayak, R.K. 2006. The Participation Scale: measuring a key concept in public health. Disability and Rehabilitation, 28, 4, 193-203.

Van de Velde, D., Bracke, P., Van Hove, G., Josephsson, S. and Vanderstraeten, G. 2010. Perceived participation, experiences from persons with spinal cord injury in their transition period from hospital to home. International Journal of Rehabilitation Research, 33, 4, 346-55.

Vasunilashorn, S., Steinman, B.A., Liebig, P.S. and Pynoos, J. 2012. Aging in place: evolution of a research topic whose time has come. Journal of Aging Research 2012:120952. Available online at doi:10.1155/2012/120952 [Accessed 08 March 2015]. 
Vik, K., Nygård, L., Borell, L. and Josephsson, S. 2008. Agency and engagement: older adults' experiences of participation in occupation during home-based rehabilitation. Canadian Journal of Occupational Therapy, 75, 5, 262-71.

Whiteneck, G. and Dijkers, M.P. 2009. Difficult to measure constructs: conceptual and methodological issues concerning participation and environmental factors. Archives of Physical Medicine and Rehabilitation, 90, Suppl 1, S22-S35.

WHO 2001. International Classification of Functioning, Disability and Health. WHO, Geneva.

Wilkie, R., Peat, G., Thomas, E. and Croft, P. 2006. The prevalence of person-perceived participation restriction in community-dwelling older adults. Quality of Life Research, $15,9,1471-9$.

Witsø, A.E., Vik, K. and Ytterhus, B. 2012. Participation in older home care recipients: a value-based process. Activities, Adaptation \& Aging, 36, 4, 297-316.

Wright-St Clair, V. 2012. Being occupied with what matters in advanced age. Journal of Occupational Science, 19, 1, 44-53.

\section{Correspondence address for corresponding author}

Paul Sugarhood

Department of Allied Health Sciences

School of Health and Social Care

London South Bank University

103 Borough Road, London, SE1 OAA

p.sugarhood@Isbu.ac.uk 
Table 1: Participants' background details

\begin{tabular}{|c|c|c|c|c|c|c|}
\hline Pseudonym & Sex & Age & Ethnicity & Home situation & Main diagnoses & Functional level * \\
\hline Irene & Female & 96 & $\begin{array}{l}\text { White } \\
\text { British }\end{array}$ & $\begin{array}{l}\text { Lives alone, owner- } \\
\text { occupied house }\end{array}$ & $\begin{array}{l}\text { Osteoarthritis (knees, } \\
\text { spine), total hip } \\
\text { replacement, bilateral } \\
\text { cataracts, cellulitis }\end{array}$ & $\begin{array}{l}\text { Assistance with PADL and DADL (formal care } \\
\text { package } 2 \text { visits/day), walks with rollator frame }\end{array}$ \\
\hline Ronan & Male & 83 & White Irish & $\begin{array}{l}\text { Lives alone, } 2^{\text {nd }} \text { floor } \\
\text { council flat }\end{array}$ & $\begin{array}{l}\text { Heart failure, osteoarthritis, } \\
\text { total hip replacement, } \\
\text { bilateral leg ulcers, cellulitis }\end{array}$ & $\begin{array}{l}\text { Assistance with PADL and DADL (formal care } \\
\text { package } 1 \text { visit/day, private home help once/week, } \\
\text { meals-on-wheels), walks with rollator frame }\end{array}$ \\
\hline Kannan & Male & 82 & $\begin{array}{l}\text { Asian } \\
\text { Indian }\end{array}$ & $\begin{array}{l}\text { Lives with spouse, } \\
\text { owner-occupied } \\
\text { house }\end{array}$ & $\begin{array}{l}\text { Severe heart failure, } \\
\text { osteoarthritis (left knee) }\end{array}$ & $\begin{array}{l}\text { Assistance with DADL (provided by spouse, family } \\
\text { and friends), walks with walking stick, very short of } \\
\text { breath }\end{array}$ \\
\hline Ella & Female & 93 & $\begin{array}{l}\text { Black } \\
\text { Caribbean }\end{array}$ & $\begin{array}{l}\text { Lives alone, council } \\
\text { bungalow }\end{array}$ & $\begin{array}{l}\text { Degenerative changes in } \\
\text { spine, frequent falls }\end{array}$ & $\begin{array}{l}\text { Assistance with DADL (provided by son), walks } \\
\text { without aids, very unsteady }\end{array}$ \\
\hline Grace & Female & 81 & $\begin{array}{l}\text { Black } \\
\text { African }\end{array}$ & $\begin{array}{l}\text { Lives alone, ground } \\
\text { floor council flat }\end{array}$ & $\begin{array}{l}\text { Rheumatoid arthritis, } \\
\text { bilateral knee } \\
\text { replacements, cellulitis, } \\
\text { type } 2 \text { diabetes }\end{array}$ & $\begin{array}{l}\text { Assistance with DADL (provided by daughter-in- } \\
\text { law), walks with 3-wheeled walker }\end{array}$ \\
\hline Norma & Female & 90 & $\begin{array}{l}\text { White } \\
\text { British }\end{array}$ & $\begin{array}{l}\text { Lives alone, private- } \\
\text { rented house }\end{array}$ & $\begin{array}{l}\text { Visual impairment, } \\
\text { osteoarthritis, diverticular } \\
\text { disease, urinary } \\
\text { incontinence, heart failure, } \\
\text { falls }\end{array}$ & $\begin{array}{l}\text { Assistance with PADL and DADL (formal care } \\
\text { package } 3 \text { visits/day), walks with rollator frame }\end{array}$ \\
\hline
\end{tabular}




\begin{tabular}{lllllll}
\hline Jasbir Singh & Male & 82 & $\begin{array}{l}\text { Asian } \\
\text { Indian }\end{array}$ & $\begin{array}{l}\text { Lives with spouse, } \\
\text { owner-occupied } \\
\text { house }\end{array}$ & $\begin{array}{l}\text { Chronic kidney disease, } \\
\text { type 2 diabetes, falls } \\
\text { (syncope), cataracts }\end{array}$ & $\begin{array}{l}\text { Assistance with DADL (provided by spouse and } \\
\text { family), walks without aids }\end{array}$ \\
\hline Kalinder & Female & 87 & $\begin{array}{l}\text { Asian } \\
\text { Indian }\end{array}$ & $\begin{array}{l}\text { Lives alone, } 2^{\text {nd }} \text { floor } \\
\text { flat in sheltered } \\
\text { housing scheme }\end{array}$ & $\begin{array}{l}\text { Heart failure, cancer, } \\
\text { depression, falls }\end{array}$ & $\begin{array}{l}\text { Assistance with DADL (provided by daughter), } \\
\text { walks without aids, very short of breath }\end{array}$ \\
\hline Harry & Male & 90 & $\begin{array}{l}\text { White } \\
\text { British }\end{array}$ & $\begin{array}{l}\text { Lives with spouse, } \\
\text { private-rented house }\end{array}$ & $\begin{array}{l}\text { Severe visual impairment, } \\
\text { osteoarthritis, urinary } \\
\text { incontinence }\end{array}$ & $\begin{array}{l}\text { Assistance with DADL (provided by spouse and } \\
\text { private home help once/week), walks with walking } \\
\text { stick }\end{array}$ \\
\hline George & Male & 91 & $\begin{array}{l}\text { Black } \\
\text { Caribbean }\end{array}$ & $\begin{array}{l}\text { Lives alone, ground } \\
\text { floor flat in sheltered } \\
\text { housing scheme }\end{array}$ & $\begin{array}{l}\text { Transient ischaemic } \\
\text { attacks, very frail following } \\
\text { treatment for colon cancer, } \\
\text { falls }\end{array}$ & $\begin{array}{l}\text { Assistance with PADL and DADL (private carers } 2 \\
\text { visits/day), walks with walking stick }\end{array}$ \\
\hline Lena & Female & 85 & $\begin{array}{l}\text { Black } \\
\text { Caribbean }\end{array}$ & $\begin{array}{l}\text { Lives with son and } \\
\text { two grandchildren, } \\
\text { owner-occupied } \\
\text { house }\end{array}$ & $\begin{array}{l}\text { Stroke, depression, } \\
\text { osteoarthritis, chronic pain }\end{array}$ & $\begin{array}{l}\text { Assistance with PADL and DADL (provided by } \\
\text { family and formal care package 1 visit/day), walks } \\
\text { with rollator frame }\end{array}$ \\
\hline
\end{tabular}

* PADL: personal activities of daily living (e.g. washing, dressing, toileting)

DADL: domestic activities of daily living (e.g. meal preparation, shopping, laundry) 


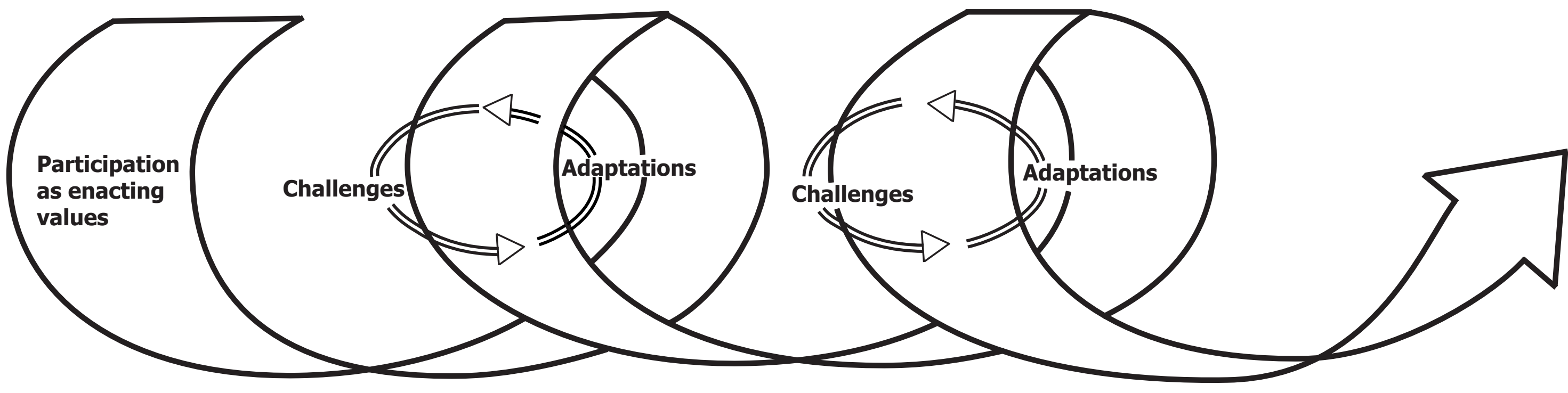

Participation as enacting values:

- Connecting with others

- Maintaining autonomy

- Affirming abilities

- Maintaining self-identity

- Doing the best you can

- Being useful

- Pursuing interests
Challenges to participation

- Being let down by health

- Losses

- Environmental influences

Environmental influences
Adapting to maintain participation:

- Interpretive processes, thinking about

things in a different way

- Selecting forms of participation and

how they are enacted

Figure 1: Participation as enacting values, an adaptive process 